\title{
Двухканальная система для записи двумерных голографических решеток
}

\author{
С.Л. Микерин, В.Д. Угожаев \\ Институт автоматики и электрометрии СО РАН \\ *E-mail:vdu@iae.nsk.su
}

DOI:10.31868/RFL2018.130-131

Интерференционная фотолитография - эффективный метод изготовления периодических структур на большой площади с масштабом до $~ 10$ нм [1] и исследования голографических материалов [2]. Доклад посвящен разработке неподвижного относительно источника излучения перестраиваемого двухлучевого интерферометра, в котором применяется механизм имитации вращательного движения. Разработка базируется на концепции вращательной перестройки периода интерференционной картины (ИК) при стабильном положения ИК относительно светоделительного элемента, предложенной и развитой в [3-7]. В этом случае возможно совмещение нескольких независимо варьируемых ИК на одной фоточувствительной среде (ФС).

Принципиальная оптическая схема такого интерферометра и обозначения представлены на рис. 1 . Линейное $W$ и угловое $\varphi$ перемещения подвижного зеркала (П3) 5, отражающего коллимированный световой пучок (КСП) 6 на входную

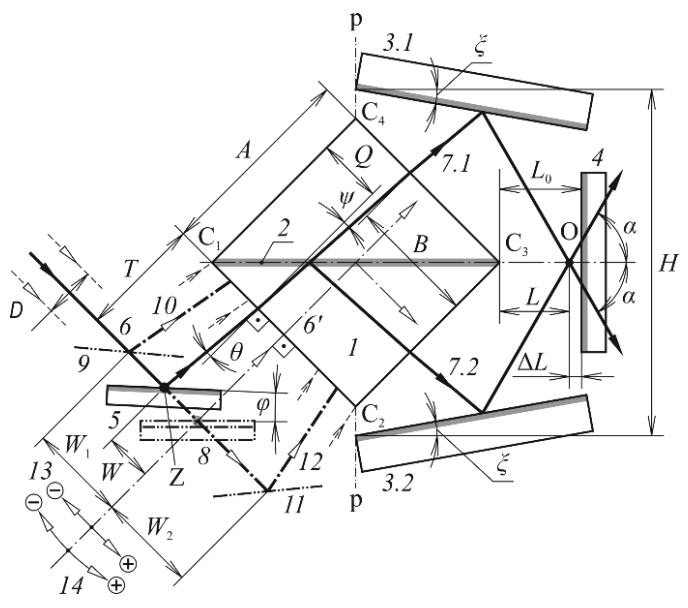

Рис. 1. Оптическая схема.

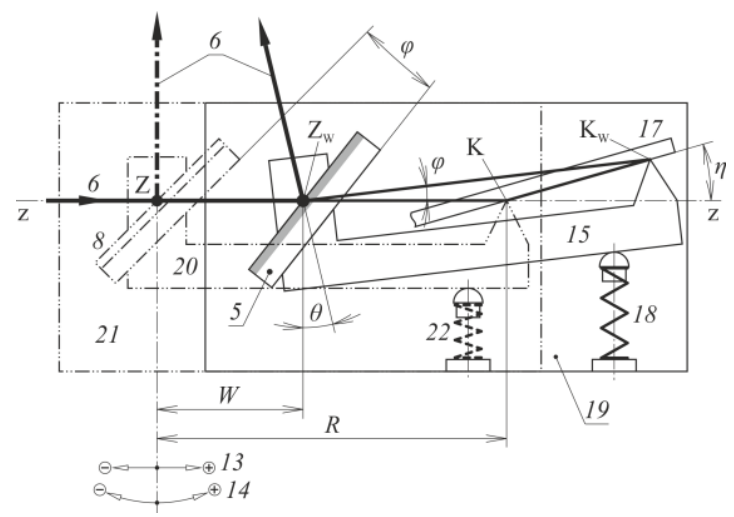

Рис. 2. Кинематическая схема механизма согласования перемещений подвижного зеркала.

поверхность светоделительного кубика 1 , должны воспроизводить взаимное согласование изменяющихся входных параметров $\theta$ и $Q$ по закону, который должен выполняться при вращении интерферометра с неподвижной ИК $(\mathrm{L}=\mathrm{const})$ :

$$
Q=A(1+\operatorname{tg} \psi)+\frac{\sqrt{2}[L \sin \alpha-(H \cos \xi-M \sin \xi) \cos (\alpha-\xi)]}{\sin (\alpha-2 \xi)+\cos (\alpha-2 \xi)},
$$

где $\alpha=\theta+2 \xi+45^{\circ}, M=A \sqrt{2}$ - длина делительного зеркала 2 , встроенного в светоделительный кубик (на рис. 1 не показана). ФС должна располагаться внутри области интерференции так, чтобы $L \cong L_{0}$. Зависимость $Q(\theta)$ согласно (1) очень близка к линейной. При малых углах падения в исследуемом интерферометре $\left(-5^{\circ} \leq \theta \leq 5^{\circ}\right)$ закон движения ПЗ также оказывается близким к линейному:

$$
\Delta W=A-D+T \Delta \alpha,
$$

где $\Delta W=W_{2}-W_{1}$ - дистанция перемещения П3, $W_{1}$ и $W_{2}$ - координаты левого 10 и правого 12 граничных положений КСП диаметром $D, \Delta \alpha-$ диапазон изме- 
нения угла $\alpha$ в разрабатываемом интерферометре; учтено, что $\operatorname{tg} \theta \approx \theta$.

Рис. 2 показывает рычажный механизм, реализующий линейную зависимость $W(\theta)$ согласно (2), в котором рычаг 15 (длина плеча $R$ ) с закрепленным на нем ПЗ при перемещении на расстояние $W$ поворачивается на угол $\varphi$ благодаря скольжению края этого рычага по наклонной направляющей 17. Учитывая малость углов $\varphi$ и $\eta$, а также используя подстановку $\varphi=\theta / 2$, можно вывести соотношение параметров $R$ и $\eta$ рычажного механизма:

$$
R=2 \Delta W \eta / \Delta \alpha
$$

Был построен опытный образец интерферометра [8] с параметрами: $A=20 \mathrm{мm}, \xi=-15^{\circ}, H=29,1 \mathrm{мм} \alpha_{0}=15^{\circ}, L_{0}=80$ мм, D $=5$ мм (рис. 1). Перемещение ПЗ в интервале $-10 \leq W \leq 10$ мм приводит к изменению угла $\alpha$ от $11^{\circ}$ до $19^{\circ}$, а периода ИК - от 1,41 до 0,83 мкм соответственно (длина волны 540 нм). При этом смещение области интерференции от ФС ничтожно мало и не превышает 26 мкм, что практически не влияет на уровень контраста ИК.

На основе данной разработки была изготовлена интерферометрическая система (рис. 3), включающая в себя пару двухлучевых интерферометров и узел совмещения, построенный на основе поляризационного кубика, и стеклянный предметный столик; габариты системы - $29 \times 20 \times 12 \mathrm{~cm}$. На горизонтальную поверхность столика выводятся две совмещенные ИК с взаимно перпендикулярными полосами и независимо регулируемыми периодами, которые могут записываться одновременно на любых образцах, в том числе с жидкими или гелеобразными ФС. Си-

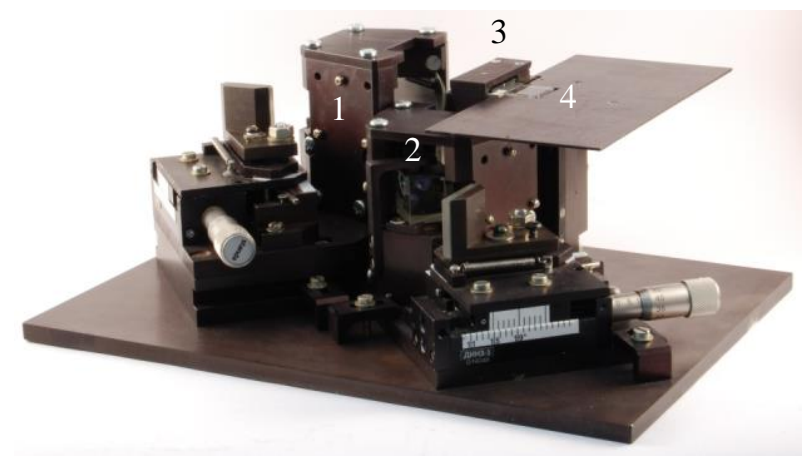

Рис. 3. Созданная интерферометрическая система: 1,2 - двухлучевые интерферометры; 3 - узел совмещения с выходной призмой; 4 - столик для размещения образцов. стема допускает использование как одного общего источника, так и двух независимых источников излучения. Результаты теста показали удовлетворительное согласие данных измерений с расчетом кинематики созданных интерферометров.

Практическая реализация интерферометра выполнена с использованием точного обрабатывающего оборудования Центра коллективного пользования «Спектроскопия и оптика» (http://ckp-rf.ru/ckp/3046/).

\section{Литература}

[1] C. Lu, R.H Lipson, Laser Photonics Rev. 4, 568-580 (2010)

[2] В.В. Шелковников, Е.В. Васильев и др., Оптика и спектроскопия 99, 806-815 (2005)

[3] С.Л. Микерин, В.Д. Угожаев, Оптика и спектроскопия 111, 1019-1025 (2011)

[4] С.Л. Микерин, В.Д. Угожаев, Автометрия 48, № 4, 20-32 (2012)

[5] S.L. Mikerin, V.D Ugozhaev. A simple two-ray interferometer tuned by rotation; Tuning of interference pattern period by rotation of interferometer itself; A rotational tuning of convergence angle in a two-ray interferometer with fixed mirrors. In: Interferometers: Fundamentals, Methods and Applications / K. Harmon Eds. Hauppauge, New York: Nova Science Publishers, 2015. ISBN 9781634836920, 9781634837163. 277 p. Ch. 7-9. P. 173-210.

[6] В.Д. Угожаев, Автометрия 52, № 2, 57-65 (2012)

[7] В.Д. Угожаев. Двухлучевой интерферометр. Патент РФ на изобретение № 2626062, Изобретения. Полезные модели № 21 (2017)

[8] С.Л. Микерин, В.Д. Угожаев. Двухлучевой интерферометр (варианты). Заявка на получение патента № 2017141671, 29.11.2017 